\title{
O ESTADO FEDERAL BRASILEIRO \\ À LUZ DA CONSTITUIÇÃO DE 1988
}

\author{
Manoel Gonçalves Ferreira Filho \\ Professor Titular da Faculdade de Direito da Universidade de São Paulo \\ Doutor pela Universidade de Paris
}

\begin{abstract}
Resumo:
O tema em exame procura precisar alguns aspectos da nova Conştituição brasileira até agora pouco estudados. Isto justifica este trabalho que não tem a pretensão senão de apontar linhas-mestras e propor uma interpretação sistemática das normas constitucionais referentes a esse importante assunto.

Desdobra-se este estudo em três partes. Delas, a primeira concerne à autonomia do Estado-membro e seu poder de autoorganização; outra, às limitações impostas a essa auto-organização; a última, à repartição de competência e especialmente ao regime da competência concorrente, sempre na Constituição Federal em vigor.
\end{abstract}

\begin{abstract}
:
The subject in discussion tries to make more precise some little studied aspects of the new Brazilian constitution. This justifies this paper, that has no other objective but show some guidelines and propose a systematic interpretation of the constitutional rules that refer to this important subject.

This study comes in three parts. The first one concerns the autonomy of the member state and its power of self-organization; the second one is about the limitations imposed to the self-organization; the last is about the attribution of competence and specially of the regime of concurrent competence, always in the Federal Constitution in force.
\end{abstract}

\section{Sumário:}

A. A autonomia do Estado-membro e seu poder de auto-organização.

B. Os limites à auto-organização dos Estados-membros no direito pátrio.

C. A repartição de competências, particularmente a competência concorrente, no Estado Federal brasileiro. 
A. A autonomia do Estado-membro e seu poder de auto-organização.

1. Unânime é na doutrina ser a autonomia a característica por excelência do Estado-membro de um Estado Federal. Longa seria a lista dos Mestres que expressamente subscrevem essa tese, como aponta Anna Cândida da Cunha Ferraz (Poder Constituinte do Estado-membro, São Paulo, Revista dos Tribunais, 1979 , p. 53).

A este respeito, salienta Machado Horta, na sua importante monografia A autonomia do Estado-membro no Direito Constitucional Brasileiro:

"A autonomia do Estado-membro constitui elemento essencial à configuração do Estado Federal" (Raul Machado Horta, ob. cit., Belo Horizonte, 1964, p. 13).

Clássica é a contraposição entre a soberania, que caracteriza o todo, o Estado Federal, e a autonomia, que caracteriza o Estado-membro (Ibid., p. 40).

Como ensina Carré de Malberg:

"Tomada na sua acepção precisa, a palavra soberania designa, não um poder, mas uma qualidade, um certo modo de ser, um determinado grau de potência (puissance). A soberania é o caráter supremo de um poder: supremo, nisto que esse poder não admite qualquer outro, nem acima, nem em concorrência com ele" (Raymond Carré de Malberg, Contribution à la Théorie Générale de l'État, Paris, Sirey, 1920, t. 1, p. 70). 
2. Em que consiste, porém, a autonomia?

$\mathrm{Na}$ doutrina estrangeira, valiosa é a análise de Costantino Mortati. Aponta ele que esse termo,

"No seu sentido etimológico (do grego: autos $=s i$ próprio, nemein=governar), quer dizer a liberdade de determinação consentida a um sujeito, resultando no poder de dar a si mesmo a lei reguladora da própria conduta, ou, mais compreensivamente, o poder de prover ao atendimento dos próprios interesses $e$, portanto, de gozar e de dispor dos meios necessários para obter uma satisfação harmônica e coordenada dos referidos interesses" (Istituzioni di Diritto Pubblico, $7^{\text {a }}$ ed., Pádua, CEDAM, v. 2, p. 694).

E acrescenta:

"No caso de que tal independência seja máxima, o termo vem a coincidir com o de soberania, e, de fato, assim foi entendido na origem" (Ibidem).

Mas, quando oposto à soberania,

"Autonomia significa o poder de autodeterminação exercitável de modo independente dentro de limites traçados pela lei estatal superior" (Ibidem).

No mesmo sentido, a doutrina brasileira. Veja-se a lição de Sampaio Dória:

"O poder que dita, o poder supremo, aquele acima do qual não haja outro, é a soberania. Só esta determina a si mesmo os limites de sua competência. A autonomia, não. $A$ autonomia atua dentro de limites que a soberania lhe tenha prescrito" (Antônio de Sampaio Dória, Direito Constitucional, $3^{\text {a }}$ ed., São Paulo, Nacional, 1953, t. 2, p. 7). 
3. Dessa autonomia resulta como um aspecto essencial a autoorganização do Estado-membro.

Observa Anna Cândida da Cunha Ferraz, com arrimo em Jellinek, Bielsa e outros:

"O primeiro conteúdo dessa autonomia é, assim, a auto-organizaçāo, ou seja, a capacidade de que é dotada a unidade federada de dar-se uma organização que descanse sobre suas próprias leis" (ob. cit., p. 54).

E acrescenta:

"Vale dizer, o primeiro elemento da autonomia estadual é a capacidade de dar-se uma Constituiçāo particular" (Ibidem).

No mesmo sentido, manifesta-se o Min. Oswaldo Trigueiro, no livro Direito Constitucional Estadual (Rio de Janeiro, Forense, 1980, $\mathbf{n}^{\mathrm{o}} 40$ ).

4. Afina-se perfeitamente com a doutrina o direito constitucional positivo brasileiro. Com efeito, ao abrir o capítulo intitulado Dos Estados Federados, o art. 25, caput, da Constituição vigente estipula:

"Os Estados organizam-se e regem-se pelas Constituiçōes e leis que adotarem, observados os princípios desta Constituição".

E aduz o seu $\S 1^{2}$ :

"São reservadas aos Estados as competências que não lhes sejam vedadas por esta Constituição".

Tais normas, aliás, estão na plena tradição do direito pátrio. Mínima é a diferença, e apenas de redação, entre o que prescrevem e o que já estava no art. 63 da Constituição de 1891, $7^{\circ}$ da Constituição de 1934, 21 da Carta de 1937, 18 da Constituição de 1946 e 13 da Constituição de 1967 (inclusive na redação dada a ela pela Emenda $n^{Q} 1$ de 1969).

Clarissimamente daí decorre a autodeterminação dos Estadosmembros, não só para estabelecer as respectivas Constituições como também as 
leis que os devem reger. Também clarissimamente daí resulta que essa autodeterminação tem limites: os que enuncia a Constituição do Estado Federal, - Brasil. Ou seja, gozam os Estados de autonomia, sendo o seu Poder Constituinte livre para fazer ou estabelecer o que não thes vedou o direito supremo, o da Constituição brasileira. Tal Poder, na verdade, procede por derivação do Poder originário, que só é próprio à Nação, de modo que é limitado, formal e materialmente por este (Cf. meu $O$ Poder Constituinte, $2^{\mathrm{a}}$ ed., São Paulo, Saraiva, 1985, n.125 e segs.).

\section{B. Os limites à auto-organização dos Estados-membros no direito pátrio.}

5. Na Constituição Federal em vigor, a limitação ao Poder Constituinte dos Estados-membros transparece já do caput do art. 25. Este manda que os Estados observem os "princípios" que ela própria estabelece. Volta à inspiração de 1891, que, sem dúvida, é a mais consentânea com o espírito do federalismo, na medida em que favorece à variedade dentro da unidade. A variedade de formulações institucionais com $\mathrm{o}$ respeito de pontos fundamentais que asseguram a unidade do todo.

Entretanto, o exame do texto vigente revela que não são postos como limites à auto-organização e ao autogoverno dos Estados apenas "princípios" propriamente ditos. Ou seja, normas gerais que exprimem valoração, ou definem linhas mestras, diretrizes. Além de princípios nesse sentido próprio, a Lei Magna exige dos Estados a observância de normas precisas, que preordenam a sua organização, que preorientam a sua atuação, segundo se vai demonstrar logo adiante:

6. Quais serão esses princípios limitativos da autonomia estadual?

Não há dificuldade em identificar alguns princípios, que a Lei Magna explicita, os quais incontestavelmente são impostos aos Estados. São os que enumera o art. 34, VII da Constituição de 1988.

$\mathrm{O}$ art. 34 prevê a intervenção federal nos Estados para, entre outras hipóteses que não interessam no momento: 
"VII- assegurar a observância dos seguintes princípios constitucionais:

a) forma republicana, sistema representativo e regime democrático;

b) direitos da pessoa humana;

c) autonomia municipal;

d) prestação de contas da administração pública, direta $e$ indireta".

Somente estes?

Pelo menos um outro parece lógico acrescentar: a separação dos Poderes.

Realmente, convém lembrar que a Constituição federal considera intocáveis, no art. $60, \S 4^{2}$, determinados princípios, os quais não podem ser abolidos sequer por emenda constitucional. Tais princípios que constituem o cerne irredutível da Constituição, se se impõem ao próprio Poder Constituinte derivado federal, a fortiori devem ser respeitados pelo Poder Constituinte dos Estados-membros que também é derivado da Lei Magna, portanto, do Poder Constituinte originário da Nação brasileira.

Ora, desses princípios intocáveis, dois: "o voto direto, secreto, universal e periódico" (art. 60, $\left.4^{2}, \mathrm{II}\right)$ e "os direitos e garantias individuais" (art. $60, \S 4^{2}$, IV), correspondem aos que já enumerara o art. 34, VII, nas alíneas "a" ("forma republicana, sistema representativo e regime democrático") e "b" ("direitos da pessoa humana"); e um é ao caso inaplicável, "a forma federativa de Estado" (art. 60, § 49, I). Mas a "separação dos Poderes" (art. 60, § 49, III), que não menciona o art. 34, VII, não pode evidentemente integrar o cerne fixo da Constituição brasileira e deixar de ser obrigatório, também, para os Estadosmembros da Federação.

7. Além desses princípios explícitos, impor-se-ão aos Estados outros, implícitos?

Sem dúvida, o exame do texto constitucional mostrará, por indução, a existência de outros princípios a informá-la. Serão, sobretudo, princípios no 
sentido de normas generalíssimas, em que se subsumem as normas definidoras ou reguladoras de institutos constitucionais.

Tais princípios "implícitos", na verdade, são sempre duvidosos, na medida em que padecem de subjetivismo (pois, cada jurista acaba por estabelecer a sua relação de princípios "implícitos"), o que enfraquece a sua respeitabilidade científica.

Cabe apontar, todavia, que esses princípios "implícitos" não podem ser invocados como limitadores da autonomia dos Estados. Se a Constituição explicitamente enumera limitações, se estas limitações, como exceções que são, devem ser interpretadas restritivamente, é descabido pretender que outros princípios também sejam imperativos para os Estados-membros.

8. Não pode ser negado, contudo, que, além dos referidos princípios, a Constituição brasileira impõe aos Estados normas específicas, que o constituinte estadual não pode afastar.

Dentre estas, avultam as que se podem chamar de "regras de preordenação institucional", por definirem a estrutura de órgãos estaduais.

Delas são exemplo as enunciadas nos arts. 27 e 28 da Lei Magna. Veja-se este art. 28:

'A eleição de Governador e do Vice-Governador de Estado, para mandato de quatro anos, realizar-se-á noventa dias antes do término do mandato de seus antecessores, e a posse ocorrerá no dia $1^{\circ}$ de janeiro do ano subseqüente, observado, quanto ao mais, o disposto no art. $77^{\prime \prime}$.

Estão aí a duração do mandato, o momento da eleição, a data da posse, e, pela remissão, o sistema eleitoral... Quer dizer, o constituinte estadual encontra prefixados esses pontos de fundamental importância no tocante à chefia do Executivo do Estado.

9. Igualmente, a Constituição federal preordenà a organização dos Estados, em muitos pontos, por meio de "regras de extensão normativa" É o 
caso, frequente no seu texto, de estender aos Estados as regras que presidem a uma instituição, ou the cometem poderes. Exemplo disto vem no art. 75, caput:

'As normas estabelecidas nesta seção aplicam-se, no que couber, à organização, composição e fiscalização dos Tribunais de Contas dos Estados e do Distrito Federal, bem como dos Tribunais e Conselhos de Contas dos Municípios"

10. Ainda limitam a autonomia dos Estados "regras de subordinação normativa" São estas as que, presentes na própria Constituição federal e direcionadas por ela a todos os entes federativos (União, Estados, Municípios), predefinem o conteúdo da legislação que será editada por eles. $\mathrm{E}$ isto, ou orientando positivamente tal conteúdo (mandando que siga determinada linha), ou negativamente (proibindo que adote certas normas ou soluções).

Exemplo de tais "regras de subordinação normativa" é o que decorre do art. 37 da Constituição brasileira, em cujo caput está:

'A administração pública direta, indireta ou fundacional, de qualquer dos Poderes da União, dos Estados, do Distrito Federal e dos Municípios obedecerá aos princípios de legalidade, impessoalidade, moralidade, publicidade e, também, ao seguinte:

A este caput seguem-se vinte e um incisos e seis parágrafos que orientam, compulsoriamente e em pormenor, a legislação dos Estados.

Da mesma forma, o art. 39 da Constituição direciona diretamente a legislação dos Estados (bem como do Distrito Federal e dos Municípios), quanto aos servidores públicos.

Observe-se que esta subordinação normativa pode ser direta ou indireta. Ela é direta (e imediata), quando deflui, sem intermediário, da Constituição federal e obriga desde logo o legislador. Ela é indireta e mediata quando se faz por meio da legislação federal obrigatória para os Estados. Esta "subordinação normativa indireta" ocorre no campo de competência legislativa 
concorrente da União e dos Estados (bem como do Distrito Federal), que enuncia o art. 24 da Constituição brasileira. Com efeito, este arligo confere à União a competência de "estabelecer normas gerais" (art. $\left.24, \S 1^{9}\right)$. Conseqüentemente, a estas normas gerais subordina as que os Estados editarem em vista de suas peculiaridades (art. $24, \S \S 2^{2}, 3^{\circ}$ e $4^{9}$ ).

11. Vale a pena, por sua importância e dificuldade, aprofundar a análise relativa à subordinação relativa indireta. Isto obriga a um exame da questão da repartição de competências no Estado Federal, para que se possa bem situar a competência concorrente e compreender suas implicações.

C. A repartição de competências, particularmente a competência concorrente, no Estado Federal brasileiro.

12. Na organização de um Estado Federal, questão fundamental é a da repartição de competências entre os entes federativos. Assinala Raul Machado Horta:

"A autonomia do Estado-Membro pressupõe a
repartição constitucional de competências para o
exercício e o desenvolvimento de sua atividade
normativa" (ob. cit., p. 50).

Duas são as técnicas pelas quais se efetiva essa repartição, segundo revela o direito comparado. Uma, mais antiga, peculiar ao chamado "federalismo dualista", caracterizada como "repartição horizontal"; outra, própria do "federalismo cooperativo", dita "repartição vertical" de competências.

13. A índole da primeira é a de separar, radicalmente, a competência dos entes federativos, por meio da atribuição a cada um deles de uma "área" própria, consistente em toda u'a "matéria" (do geral ao particular ou específico), a ele privativa, a ele reservada, com exclusão absoluta da participação, no seu exercício, por parte de outro ente. Daí falar-se, a propósito de tais competências, em competências "privativas" ou "reservadas". 
14. A da segunda é a de dividir u'a mesma "matéria", em diferentes níveis, entre diversos entes federativos. Assim, u’a mesma "matéria" é atribuída concorrentemente a entes federativos diversos, sempre, porém, em níveis diferentes: a um atribui-se o estabelecimento de normas gerais, a outro, das normas particulares ou específicas.

Fala-se neste caso em competência concorrente, pois relativamente a uma só e mesma matéria concorre a competência de mais de um ente político.

Cumpre notar que a competência concorrente pode ser de duas espécies: a cumulativa e a não-cumulativa (V. a este propósito meus Comentários à Constituiçāo Brasileira, $6^{\mathrm{a}}$ ed., São Paulo, Saraiva, 1986, p. $98 \mathrm{e}$ segs.).

A cumulativa existe sempre que não há limites prévios para o exercício da competência, ou por parte de um ente, seja a União, seja o Estadomembro. Claro está que, por um princípio lógico, havendo choque entre norma estadual e norma federal num campo de competência cumulativa, prevalece a regra da União. É o que exprime o brocardo alemão: Bundesrecht bricht Landesrecht.

A não-cumulativa é que propriamente estabelece a chamada repartição "vertical". Com efeito, dentro de um mesmo campo material (concorrência "material" de competência), reserva-se um nível superior ao ente federativo mais alto a União - que fixa os princípios e normas gerais, deixandose ao ente federativo que é o Estado-membro a complementação. Diz-se, por isto, que cabe ao Estado-membro uma competência "complementar". Admite-se até, que à falta dessas normas gerais, o Estado-membro possa suprir essa ausência (competência "supletiva"). Entretanto, quem supre complementa. A norma que vem suprir um branco, evidentemente, complementa o ordenamento. Da mesma forma, quem complementa de certo modo supre, já que fecha um claro ao desdobrar a norma geral. Dessa correlação nasce o emprego impróprio das expressões competência "complementar" e competência "supletiva", em que incidem, por vezes, os próprios textos constitucionais (como era o caso do art. $8^{2}$, parágrafo único, da Constituição anterior). A essas expressões a Constituição vigente preferiu outra: competência "suplementar", com igual ambiguidade. 
15. É evidente que a técnica da repartição horizontal favorece à independência recíproca dos entes federativos entre si, enquanto a da repartição vertical leva, forçosamente, a uma coordenação na atuação desses entes. Aí está a razão básica por que o federalismo "dualista", que enfatiza a separação entre os entes federativos, prefere a primeira, enquanto o federalismo "cooperativo", que encarece a colaboração entre os entes políticos de nível diverso, se inclina pela segunda.

Entretanto, deve-se observar que mesmo no federalismo cooperativo não são todas as matérias que sofrem a repartição de tipo vertical; persistem, sempre, matérias reservadas, ou privativas, de determinado ente federativo, seja União (principalmente), sejam os Estados-membros.

16. Assim é, no Direito Pátrio. A Constituição brasileira de 1988 adota, ao repartir competências entre a União, de um lado, os Estados-membros e o Distrito Federal, de outro, ora a técnica da repartição horizontal, ora a técnica da repartição vertical.

Com efeito, no art. 22 enuncia ela o campo da competência privativa da União. No art. 30, o da competência reservada dos Municípios (que na atual Constituição são indiscutivelmente entes federativos). E no art. $25, \S 1^{\circ}$ determina, ainda que indiretamente, o campo da competência privativa dos Estados: tudo aquilo que aos Estados não for vedado pela Constituição. Ora, o que é vedado aos Estados-membros forçosamente é o que é atribuído a outro ente federativo: União, ou Município.

No art. 24, a seu turno, a Constituição vigente enumera a competência concorrente, aquela que põe em comum à União, aos Estados (e ao Distrito Federal, que no tocante a competências se equipara aos Estadosmembros da Federação).

17. É importante analisar mais detidamente o regime a que a nova Constituição submete as competências concorrentẹs. Para isto, é mister ponderar os quatro parágrafos do citado art. 24. Dispõem eles:

"§ $1^{Q}$ - No âmbito da legislação concorrente, a competência da União limitar-se-á a estabelecer normas gerais. 
$\S 2^{Q}-A$ competência da União para legislar sobre normas gerais não exclui a competência suplementar dos Estados.

$\S 3^{9}$ - Inexistindo lei federal sobre normas gerais, os Estados exercerão a competência legislativa plena, para atender a suas peculiaridades.

$\S 4^{2}-$ A superveniência de lei federal sobre normas gerais suspende a eficácia da lei estadual, no que lhe for contrário."

Quais as decorrências desses parágrafos?

A primeira, indiscutível, é a de que a competência concorrente, na Constituição em vigor, é de caráter não-cumulativo. Há dois níveis previstos a seu respeito: um, mais alto, o das normas gerais; outro, mais baixo, de complementação (ou "suplementação", como fala o parágrafo $2^{2}$ ).

O nível superior o das normas gerais - é privativo da União. Temse aqui verdadeira competência reservada da União, que não pode ser invadida pelos Estados.

Prevê o Texto, é certo, que a inexistência de normas federais de caráter geral enseja a competência supletiva dos Estados-membros, mas, apenas, "para atender a suas peculiaridades" (§ 3o). Quer dizer, a Constituição admite que, "para atender a suas peculiaridades", na falta de lei federal de normas gerais - frise-se o Estado fixe princípios, mas em vista da competência que lhe $E$ natural, a de complementar as normas gerais federais.

Não é fácil conceituar "normas gerais", pelo ângulo positivo. Podese afirmar, e corretamente, que "normas gerais" são princípios, bases, diretrizes, que hão de presidir todo um subsistema jurídico. Sempre haverá, no entanto, em face de casos concretos, dúvida até onde a norma será efetivamente geral, a partir de onde ela estará particularizando.

Mais fácil é determinar o que sejam "normas gerais", pelo ângulo negativo. Quer dizer, indicar os caracteres de uma norma que não é "geral", é complementar, é particularizante.

Portanto, não pode uma "norma geral" descer a particularizações, que visem a atender a peculiaridades regionais. 
Reitere-se que, mesmo inexistindo normas gerais editadas pela União, o Estado não pode fixá-las senão na medida em que isto for indispensável, "para atender a suas peculiaridades" É o que claramente especifica o art. 24, § $3^{\circ}$ da Constituição de 1988.

18. Neste último caso, havendo o Estado exercido a competência supletiva a ele deferida pelo parágrafo $3^{\circ}$, a superveniência de lei federal que edite essas normas gerais, tem por decorrência a perda da eficácia da lei estadual, "no que for contrário" ao prescrito na legislação federal.

Note-se que as normas estaduais que contraditarem as regras gerais editadas pela União no campo da competência concorrente, são inconstitucionais. De fato, na competência concorrente, há também uma divisão de competência, embora vertical. A União fica com o geral, os Estados-membros com o particular. É o que resulta do art. $24, \S 1^{2}$ especialmente.

Mais. Se, inexistindo regra geral federal, é editada norma geral pelo Estado, com base no $\S 3^{\circ}$ desse artigo, caso venha a ser posta regra geral pela União que colida com essa norma geral estadual anterior, esta última é colhida pela chamada "inconstitucionalidade superveniente" (cf. Jorge Miranda, Manual de Direito Constitucional, $2^{\mathrm{a}}$ ed., Coimbra, Coimbra, 1987, $\mathrm{n}^{\mathrm{Q}} 63$ ). Perde ela eficácia, como está no $\S 4^{\ell}$ do art. 24 ; não $e$, rigorosamente falando, revogada.

E isto tanto se aplica a normas gerais que haja o Estado promulgado, como, segundo é óbvio, às normas de complementação destinadas a atender peculiaridades suas.

19. A última conclusão é a de que a competência típica dos Estados, no campo concorrente, é a de complementação das normas gerais, "para atender a suas peculiaridades". Estas, as normas gerais, fixam o que deve ser uniforme no Estado Brasileiro, pois este é um Estado, embora composto; a estas normas gerais cada Estado pode, e deve, complementar, em função de suas peculiaridades. 
Pode o Estado, portanto, complementar a legislação nacional de normas gerais, isto é, cditar normas que adicionem pormenores à regra primitiva nacional. Vale, porém, recordar a advertência de Carlos Maximiliano:

"Não é lícito (ao Estado), entretanto, INOVAR; cada Estado ficará adstrito à orientação traçada pelas normas positivas promulgadas pela Uniāo. $A$ interferência da legislatura local visará apenas as NECESSIDADES E PECULLARIDADES REGIONAIS, providências de ordem pública, que indiscutivelmente se coadunem com o sistema, as exigências e as outorgas de origem federal" (Comentários à Constituição Brasileira, $5^{\text {a }}$ ed., Rio de Janeiro, Freitas Bastos, 1954, v. 1, p. 205, ênfase no texto original).

Esta lição de Carlos Maximiliano caracteriza perfeitamente o que são normas complementares. São complementares ou particularizantes as normas que visem "necessidades e peculiaridades regionais", e isto, com a ressalva que o Mestre acentua, desde que essa particularização se coadune "com o sistema, as exigências $e$ as outorgas de origem federal" (Ibidem). Note-se que Maximiliano escrevia sem o arrimo do que está na parte final do art. 24, § $3^{2}$, que vincula a competência dos Estados ao atendimento de "suas peculiaridades"

São Paulo, 14 de fevereiro de 1990 